\title{
Transition Behavior and Dielectric Properties in Trifluoroethylene and Vinylidene Fluoride Copolymers
}

\author{
Toshiharu Yagi, Masayoshi TAtemoto, and Jun-ichi SAKo \\ Application Research Department, Chemical Division, Daikin Kogyo Co., Ltd., \\ 700-1, Hitotsuya, Settsu, Osaka 564, Japan.
}

(Received July 6, 1979)

\begin{abstract}
S: The transition behavior and dielectric properties of trifluoroethylene (TrFE)vinylidene fluoride (VDF) copolymers were studied. The DSC and X-ray diffraction measurements indicated that the conformation of the polymers was in a crystalline state throughout the entire polymer composition, and crystallized isomorphically. In the thermal expansion measurement of the 56: 44 TrFE-VDF copolymer, two breaks were observed, indicating two glass-to-rubber transitions. These two transitions were also observed in a mechanical relaxation study with peaks at $40^{\circ} \mathrm{C}$ (designated as $\beta_{1}$ ) and $-20^{\circ} \mathrm{C}$ (designated as $\beta_{2}$ ), measured at $35 \mathrm{~Hz}$. The $\beta_{1}$-transition was tentatively assigned to the micro-Brownian motion of the main chain in the amorphous phase rich in TrFE-units; the $\beta_{2}$-transition was assigned to the micro-Brownian motion of the main chain in the amorphous phase, rich in VDF-units. It was also found that the dielectric constant $\varepsilon^{\prime}$ of TrFE-VDF copolymer took on a maximum at $55 \mathrm{~mol} \%$ VDF content. The numerical value of $\varepsilon^{\prime}$ was 15 (at $1 \mathrm{kHz}$ and at $22^{\circ} \mathrm{C}$ ) and about 1.7 times larger than those of poly(trifluoroethylene) and poly(vinylidene fluoride) homopolymers.

KEY WORDS Trifluoroethylene-Vinylidene Fluoride Copolymers / Mechanical Relaxation / Dielectric Relaxation / Glass Transition / Dielectric Property / Melting Temperature / Isomorphism / Crystal Form /
\end{abstract}

In previous papers, ${ }^{1,2}$ the authors reported the preparation and microstructure of trifluoroethylene (TrFE)-vinylidene fluoride (VDF) copolymers. The monomer reactivity ratios $\left[r_{1}(\mathrm{TrFE})=0.5\right.$ and $\left.r_{2}(\mathrm{VDF})=0.7\right]$ and high resolution ${ }^{19} \mathrm{~F}$ NMR studies indicated that the TrFE-VDF copolymer system was in a random configulation.

Recently, we reported the transitions and relaxations of poly(trifluoroethylene) [PTrFE, $-\left(\mathrm{CF}_{2}-\mathrm{CFH}-\right)_{n}-\mathrm{]}$ obtained by mechanical and dielectric measurements. ${ }^{3}$ It was found that PTrFE exhibited two transitions with peaks at 50 and $-20^{\circ} \mathrm{C}$ in a mechanical relaxation measurement at $35 \mathrm{~Hz}$; the upper-transition was assigned to microBrownian motion of the main chain in the amorphous region, and the lower-transition was assigned to local molecular motion in both the amorphous and crystalline regions. The glass transition temperature of PTrFE is around $40^{\circ} \mathrm{C}^{3-5}$

The relaxation mechanism of poly(vinylidene fluoride) [PVDF, $-\left(\mathrm{CF}_{2}-\mathrm{CH}_{2}-\right)_{n}-$ ] has been studied in detail by mechanical, ${ }^{6-8}$ dielectric,,${ }^{6,9-17}$ and
$\mathrm{NMR}^{18-20}$ methods. PVDF polymer exhibited three transitions with peaks at $50^{\circ} \mathrm{C}$ (designated as $\alpha$ ), $-35^{\circ} \mathrm{C}$ (designated as $\beta$ ), and $-80^{\circ} \mathrm{C}$ (designated as $\gamma$ ). According to these studies, the $\alpha$-transition was assigned to molecular motion in the crystal region including the lamellar surface and to crystalline defects; the $\beta$-transition was assigned to microBrownian motion in the amorphous region; the $\gamma$ transition was assigned to local molecular motion in the amorphous region. The glass transition temperature of PVDF is around $-40^{\circ} \mathrm{C} . .^{13,21}$

$\mathrm{PTrFE}$ is classified as a highly crystalline polymer like other fluorinated ethylene polymers. ${ }^{3}$ The crystal form of PTrFE has not been established yet. However, there are some reports claiming that the crystal form is hexagonal and that the main chain takes on a helical conformation in the crystal. ${ }^{22,23}$

$\mathrm{X}$-ray and infrared studies have shown that there are three crystal forms in $\mathrm{PVDF}^{24-29}$; the $\alpha$-crystal form (form II) has a trans-gauche-trans-gauche ( $T G T G^{\prime}$ ) conformation, and the $\beta$-crystal form (form I) has a planar zigzag conformation. The $\gamma$-crystal 
form (form III) is closely similar to the $\beta$-crystal form. ${ }^{29}$ It was indicated that the $\beta$-crystal form of PVDF has a spontaneous polarization and the possibility of ferroelectricity. ${ }^{30}$

PVDF is distinguished among the crystalline polymers by a high dielectric constant such as $\varepsilon^{\prime}=8.5$, at $1 \mathrm{KHz}$ and at $22^{\circ} \mathrm{C}$. Recently, this material has drawn attention as a new transducer material because of its interesting piezoelectricity and pyroelectricity properties. ${ }^{30-41}$ Many reports claim that these properties are closely correlated with the existence of an oriented dipole structure in crystal. ${ }^{30-36} \mathrm{PTrFE}$ is also a high $\varepsilon^{\prime}$ material $\left(\varepsilon^{\prime}=7.5\right.$ at $1 \mathrm{KHz}$ and at $22^{\circ} \mathrm{C}$ ) like PVDF. ${ }^{3}$ It should be interesting, therefore, to examine the dielectric properties of the TrFE-VDF copolymers.

The purpose of this study is to report (1) the crystal properties of the TrFE-VDF copolymers, (2) their transition behaviors, and (3) the estimation of their dielectric properties. The crystal properties were studied by means of DSC, X-ray, and infrared measurements. The transition behavior was studied by mechanical and dielectric relaxation measurements. The transition behaviors of PTrFE and TrFE-rich copolymers have been reported elsewhere. ${ }^{3}$ This study deals with the TrFE-VDF copolymers (30 to $90 \mathrm{~mol} \% \mathrm{VDF}$ ). The dielectric properties of copolymers will be discussed in terms of (1) the magnitude of dipole moments of repeating units, (2) the position and direction of the dipole with respect to the chain backbone, (3) the freedom of the dipole rotation, and (4) the crystal form of the TrFEVDF copolymers; i.e., the possibility of a spontaneous polarization in crystal. A study of piezoelectricity of the TrFE-VDF copolymers will be reported in a subsequent paper.

\section{EXPERIMENTAL}

The preparation of the TrFE-VDF copolymers was described in our previous paper. ${ }^{2}$ The physical properties of these copolymers are tabulated in Table I.

A thermal analysis was performed with a differential scanning calorimeter (Perkin-Elmer DSC-2). An Aluminum pan was used to contain the specimen and the weight of each specimen was about $10 \mathrm{mg}$. A heating rate of $10^{\circ} \mathrm{C} \mathrm{min}{ }^{-1}$ was used in all experiments. The maximum DSC endotherm of fusion was assumed to be the melting temperature $T_{\mathrm{m}}$ of the polymer sample. The temperature calibration was based on indium, tin and lead standard.

Table I. Physical properties of samples

\begin{tabular}{|c|c|c|c|c|c|}
\hline \multirow{2}{*}{$\begin{array}{l}\text { Sample } \\
\text { code }\end{array}$} & \multirow{2}{*}{$\frac{\text { VDF content }}{\mathrm{mol} \%}$} & \multirow{2}{*}{$\frac{[\eta]}{\mathrm{dl} \mathrm{g}^{-1}}$} & \multirow{2}{*}{$\frac{R^{\mathrm{a}}}{{ }^{\circ} \mathrm{C} / \mathrm{min}^{-1}}$} & \multirow{2}{*}{$s_{\mathrm{p}}^{\mathrm{b}}$} & \multirow{2}{*}{$\frac{X_{\mathrm{c}}^{\mathrm{c}}}{\%}$} \\
\hline & & & & & \\
\hline A-1 & 0 & 5.9 & 50 & 1.9905 & 53 \\
\hline A-2 & 12.5 & & 50 & 1.9657 & \\
\hline A-3 & 30 & 3.6 & 50 & 1.9385 & \\
\hline A-4 & 36 & 2.1 & 50 & 1.9296 & \\
\hline A-5-1 & 44 & 1.8 & 50 & 1.8927 & 64 \\
\hline A-5-2 & 44 & 1.8 & $\begin{array}{l}\text { Ice water } \\
\text { quenched }\end{array}$ & & 57 \\
\hline A-5-3 & 44 & 1.8 & 0.3 & & 76 \\
\hline A-6 & 54 & 4.7 & 50 & 1.8943 & \\
\hline A-7 & 60 & 5.1 & 50 & 1.8859 & \\
\hline A-8 & 63 & 2.3 & 50 & 1.8806 & \\
\hline A-9 & 85 & 2.7 & 50 & 1.8663 & \\
\hline A-10 & 90 & & 50 & 1.8206 & \\
\hline A-11 & 98 & 3.8 & 50 & 1.7852 & \\
\hline A-12 & 100 & 2.0 & 50 & 1.7560 & \\
\hline
\end{tabular}

a Cooling rate in the molding process.

b Specific gravity measured at $23^{\circ} \mathrm{C}$.

c Degree of the crystallinity obtained by wide-angle X-ray measurements. 
Wide-angle X-ray diffraction profiles were obtained with a Rigaku-Denki diffractometer. The specimens used for X-ray diffraction measurements were heat-pressed sheets whose cooling rate was about $50^{\circ} \mathrm{C} \mathrm{min}-1$. The degree of crystallinity was also estimated by the $\mathrm{X}$-ray diffraction method.

Infrared spectra were recorded on a JapanSpectroscopic IR-G Spectrometer. The specimen films were prepared by the heat-pressed method.

Mechanical relaxation measurements were carried out by means of the viscoelastometer (ToyoBowldwin Vibron DDV-2 and Iwamoto Seisakusho Spectrometer VES-2) over temperatures ranging from -120 to $100^{\circ} \mathrm{C}$ and frequencies ranging from 3 to $100 \mathrm{~Hz}$, at a heating rate of about $0.5^{\circ} \mathrm{C} \mathrm{min}^{-1}$. The specimens used for mechanical relaxation measurements were films from 0.05 to $0.5 \mathrm{~mm}$ thickness molded by the heat-press method. In sample A-5 (44 mol\% VDF), three specimens of different crystallinity were prepared by changing the time and temperature of annealing or quenching. The details of the samples are given in Table I.

Dielectric measurements were carried out by means of a transformer bridge (Ando-Denki TR$10 \mathrm{C}$ ) at frequencies ranging from $30 \mathrm{~Hz}$ to $300 \mathrm{KHz}$ and over temperatures ranging from -150 to $100^{\circ} \mathrm{C}$. The specimens used for dielectric measurements were heat-pressed circular-sheets 1.0 to $1.3 \mathrm{~mm}$ in thickness and $50 \mathrm{~mm}$ in diameter. Aluminum was evaporated on the specimen surfaces in high vacuum.

The linear thermal expansion was measured by a quartz-tube dilatometer. The cylindrical specimen for linear thermal expansion was about $10 \mathrm{~mm}$ in height and $7 \mathrm{~mm}$ in diameter and was annealed for 30 hours at $100^{\circ} \mathrm{C}$ so as to remove the strain.

\section{RESULTS AND DISCUSSION}

\section{Melting Temperatures}

Figure 1 shows DSC curves of the TrFE-VDF copolymers. The double endothermic peaks (designated $T_{\mathrm{m}}$ and $T_{\mathrm{m}}{ }^{\prime}$ ) were observed in VDF-rich copolymers in the region from 54 to $90 \mathrm{~mol} \%$ VDF content; $T_{\mathrm{m}}$ is the primary melting temperature observed on the high temperature side, and $T_{\mathrm{m}}{ }^{\prime}$ the secondary melting temperature, was observed on the lower temperature side. The peak-area ratio of $T_{\mathrm{m}}$ to $T_{\mathrm{m}}{ }^{\prime}$ is about $8: 1$ in the $15: 85 \mathrm{TrFE}-\mathrm{VDF}$ copolymer (sample A-10).

The endothermic peak of primary melting was

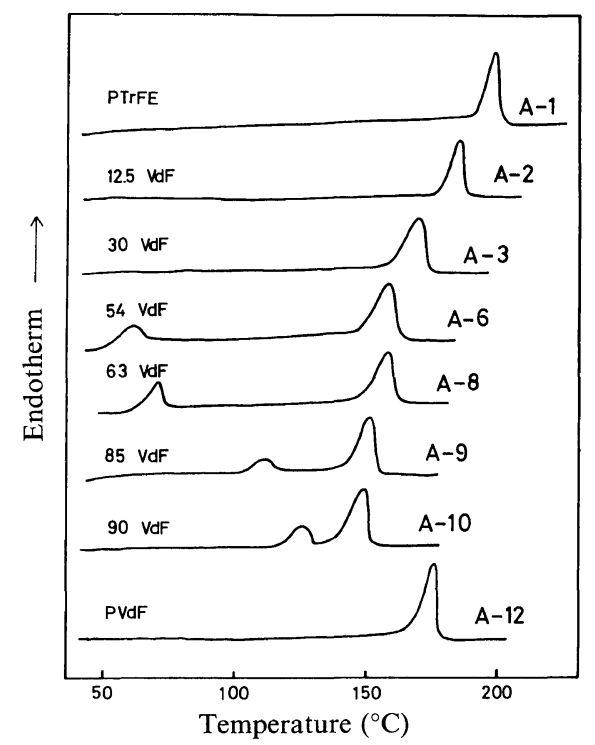

Figure 1. DSC thermograms of the TrFE-VDF copolymers.

observed clearly throughout the composition of each polymer. These results indicate that the TrFE-VDF copolymers are completely crystalline throughout their composition. In most random copolymer systems, the introduction of second component usually brings about a reduction in crystallinity. ${ }^{42}$

Figure 2 shows a change in melting temperature with change in polymer composition (data are reproduced from Figure 1). The $T_{\mathrm{m}}$ takes a minimum value at $90 \mathrm{~mol} \%$ VDF content. On the other hand, $T_{\mathrm{m}}{ }^{\prime}$ appears at about $50 \mathrm{~mol} \%$ VDF content, and increases with increasing VDF content. The extrapolation of the $T_{\mathrm{m}}{ }^{\prime} v s$. the polymer composition curve to $100 \%$ VDF gives $T_{\mathrm{m}}$ of PVDF.

It is generally recognized that the two endotherms appearing in DSC measurement, arise from the different sources: the thermal history of the sample, and the characteristic nature of polymer. ${ }^{43,44}$ Examples of thermal history are the recrystallization during cooling after annealing and the additional crystallization during the DSC measurement. An example of the characteristic nature of polymer is the solid phase transition in crystal, a partial melt of the crystal phase, or the melting of two different crystal phases initially coexisting.

DSC measurement for sample A-8 $(63 \mathrm{~mol} \%$ VDF) indicates that both $T_{\mathrm{m}}$ and $T_{\mathrm{m}}{ }^{\prime}$ are 


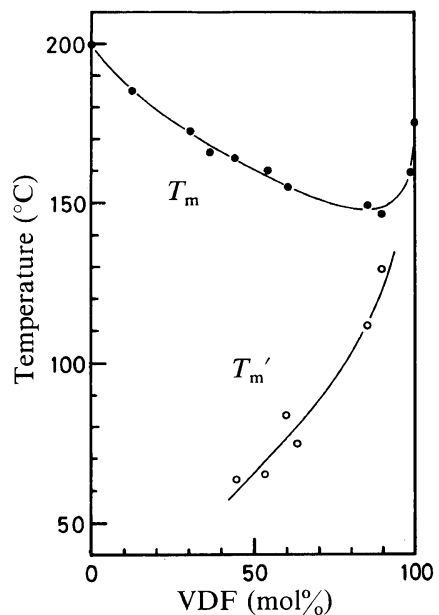

Figure 2. Change in the melting temperature with polymer composition for the TrFE-VDF copolymer system. $T_{\mathrm{m}}$ is the primary melting temperature and $T_{\mathrm{m}}{ }^{\prime}$ is the secondary melting temperature.

independent of the heating rate and annealing process. These results indicate that the $T_{\mathrm{m}}{ }^{\prime}$ peak originally arises from the nature of the TrFE-VDF copolymers.

More accurate studies of this $T_{\mathrm{m}}{ }^{\prime}$ transition are now being carried out at our laboratory, and will be reported soon.

\section{Crystal Form}

Figure 3 shows X-ray diffraction profiles of the TrFE-VDF copolymers. The fact that the diffraction peaks are observed clearly throughout the range of polymer composition supports the above consideration that the TrFE-VDF copolymer is in a crystalline state throughout the entire range of the polymer composition. The X-ray diffraction profile changes considerably between sample A-9 and A-10 (85 and $90 \quad \mathrm{~mol}^{\%} \%$ VDF content, respectively). Sample A-12 shows a typical profile of the $\alpha$-form crystal of PVDF, i.e., four strong diffractions. $^{25}$ The $\mathrm{X}$-ray diffraction profile of sample A-10 resembles that of PVDF except for the diffraction angles. The $\mathrm{X}$-ray diffraction profiles of sample A- 1 to A-9 ( 0 to $85 \mathrm{~mol} \%$ VDF content) are quite similar to each other, and show only one strong diffraction.

Similar crystal form changes in the TrFE-VDF copolymers are also observed in infrared measurement. Figure 4 shows the infrared spectra of the TrFE-VDF copolymers in the region from 600 to $1100 \mathrm{~cm}^{-1}$. The infrared spectrum of sample A-12 (PVDF) shows the typical pattern of the $\alpha$-form crystal of PVDF. ${ }^{45,46}$ Sample A-10 also shows the pattern of the $\alpha$-form crystal, i.e., five absorption peaks in the region from 600 to $1100 \mathrm{~cm}^{-1}$. However, the peak intensities are different for samples A-10

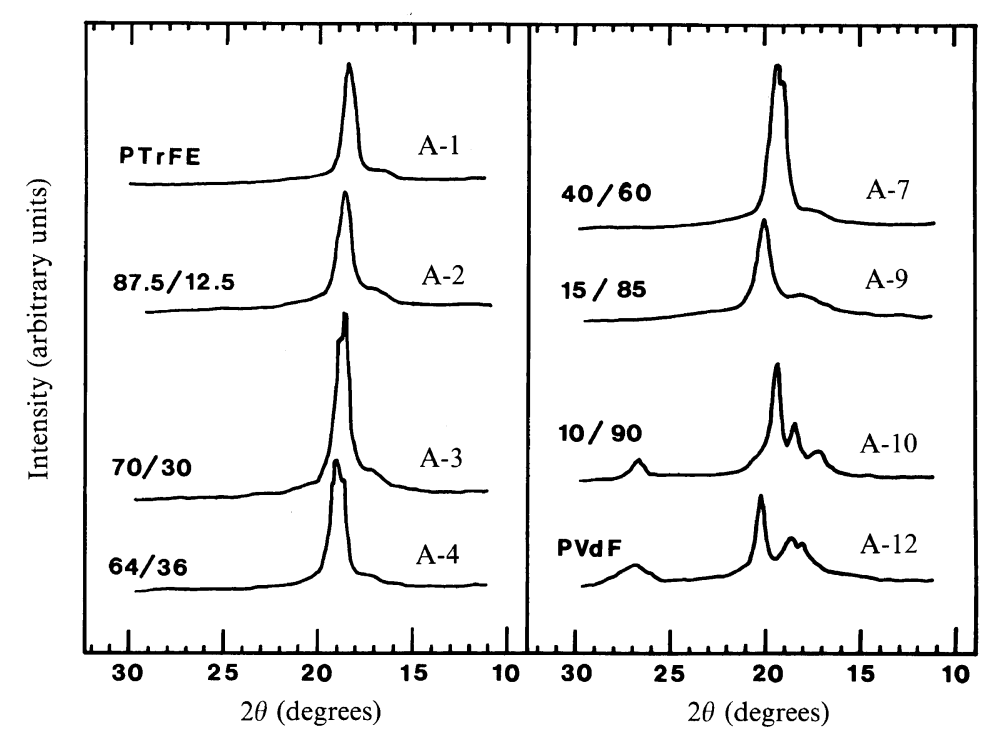

Figure 3. X-ray diffraction profiles of the TrFE-VDF copolymers. 

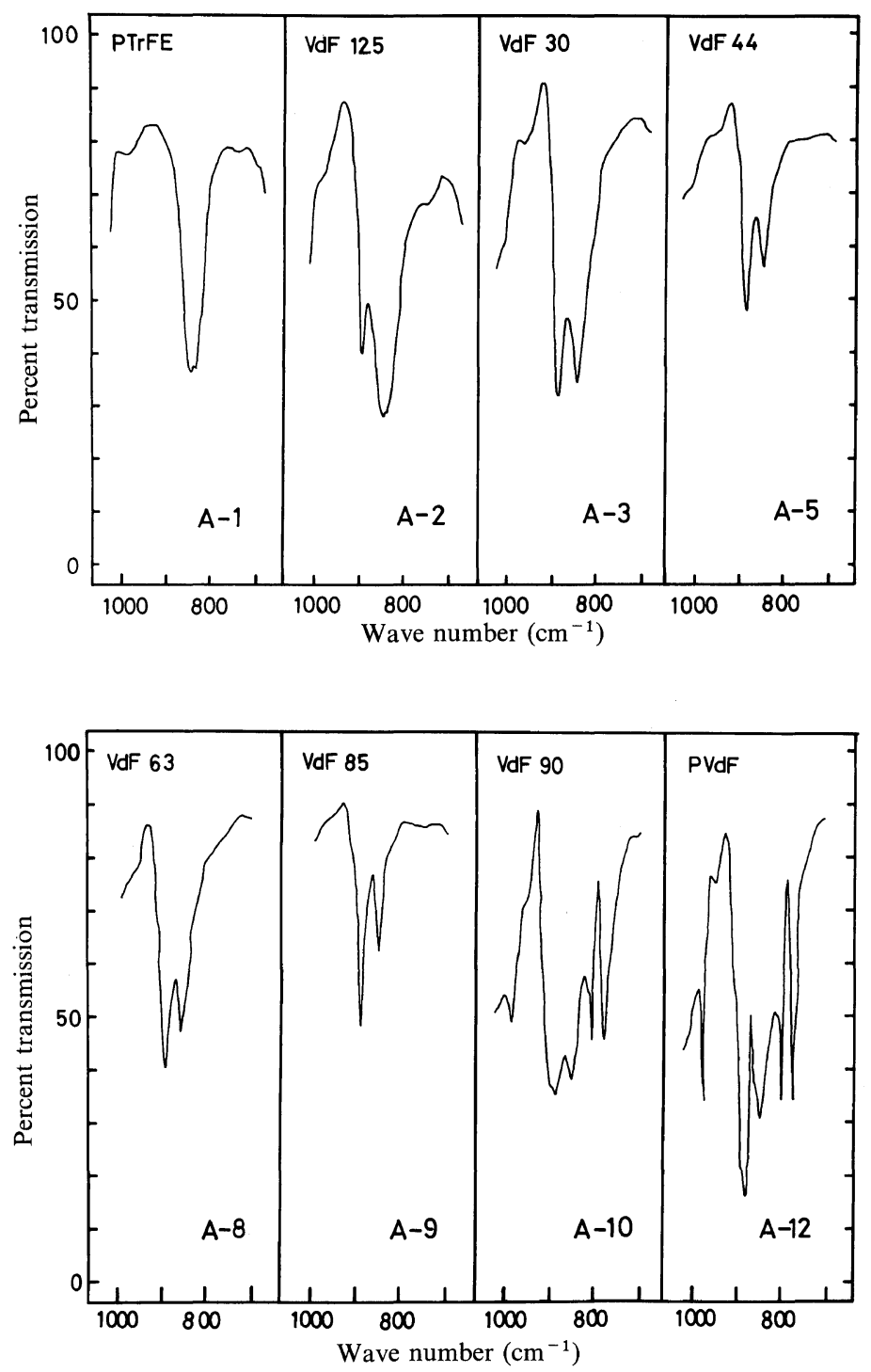

Figure 4. Infrared spectra of the TrFE-VDF copolymers.

and A-12. The infrared spectrum patterns in samples A-9 and A-10 differ considerably. In sample A-9, only two peaks ( 885 and $852 \mathrm{~cm}^{-1}$ ) are observed. The spectrum pattern of sample A-10 is very similar to that of the $\beta$-form crystal, ${ }^{4,46}$ meaning that the crystal form of the TrFE-VDF copolymer changes from the $\alpha$ - to $\beta$-form between an 85 to $90 \mathrm{~mol} \%$ VDF content. This result agrees well with X-ray measurement studies. The infrared spectra profiles of samples A-2 to A-9 resemble each other, and show the characteristic profile of the $\beta$-form crystal, indicating that the TrFE-VDF copolymers take on a trans or trans-like conformation in crystal throughout the entire polymer composition (12.5 to $85 \mathrm{~mol}^{\%}$ \% VDF).

According to the energy calculation of atactic PTrFE crystal by Kolda and Lando, ${ }^{23}$ the trans conformation of the polymer chain is stable, provided the percentage of the head-to-head defects is about $20 \%$. High resolution ${ }^{19} \mathrm{~F}$ NMR and 
simulation studies ${ }^{1}$ indicated that the polymer chain of PTrFE (prepared by radical polymerization method at $22^{\circ} \mathrm{C}$ ) contained about $25 \%$ head-to-head defects. Therefore, the probability that the PTrFE molecules take trans conformation in crystal is large. According to an electron diffraction study by Gal'perin and Strogalin, ${ }^{22}$ the polymer chain of PTrFE takes on a helical conformation twisted from the trans conformation in crystal.

In conclusion, the crystal form of the TrFE-VDF copolymers may be classified into three parts: (1) $T G T G^{\prime}$-conformation ( $\alpha$-form) in PVDF and 90 $\mathrm{mol} \%$ VDF copolymer; (2) trans or trans-like conformation ( $\beta$ - or $\beta$-like form) in 12.5 to $85 \mathrm{~mol} \%$ VDF copolymers; (3) helical conformations in PTrFE. The $\alpha$ - and $\beta$-form crystal of PVDF can be transformed into each other by appropriate thermal treatment. ${ }^{24}$ However, the TrFE-VDF copolymer (12.5 to $85 \mathrm{~mol} \%$ VDF) always shows the $\beta$-form crystal and does not transform into the $\alpha$-form crystal by any thermal treatments.

Lando and Doll ${ }^{25}$ reported that the TrFE-VDF copolymer ( $83 \mathrm{~mol} \%$ VDF content) did not take on the $\alpha$-form but the $\beta$-form in crystal, as shown by the $\mathrm{X}$-ray diffraction method, and they considered that the rotational barrier between $\mathrm{CF}_{2}$ and $\mathrm{CFH}$ group (in TrFE unit), or $\mathrm{CF}_{2}$ and $\mathrm{CF}_{2}$ group (head-to-head structure of $\operatorname{TrFE}$ and VDF) prevented the $T G T G^{\prime}$ conformation in crystal. A similar change in crystal morphology was also observed in the tetrafluoroethylene-VDF copolymer system. ${ }^{25}$

Figure 5 shows a change in the lattice parameter with polymer composition. In the figure, the symbol $\alpha$ represents the $T G T G^{\prime}$ conformation in crystal; the symbol $\beta$ represents the trans or trans-like

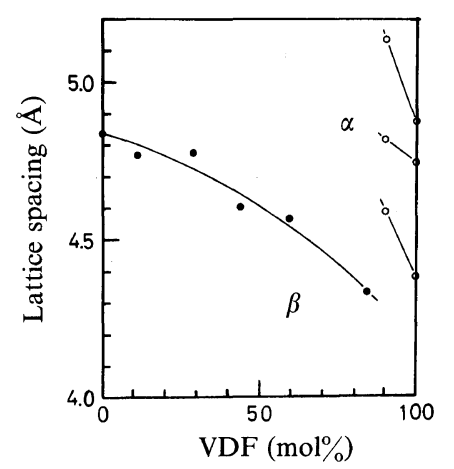

Figure 5. Change in the lattice parameter with polymer composition. conformation. The lattice parameter changes almost linearly from PTrFE to PVDF, independent of the polymer morphology. This indicates that the TrFE and VDF units disolve each other in crystal; i.e., the TrFE-VDF copolymer system seems to cocrystallize isomorphically.

Usually, an isomorphism system shows continuous variation in the melting temperature with polymer composition. ${ }^{47}$ This has become widely accepted as a criterion for isomorphous replacement. However, a number of copolymer systems are also reported in which the isomorphous replacement takes place without showing a linear relationship between $T_{\mathrm{m}}$ and the polymer composition. ${ }^{48}$ As shown in Figure 2, the $T_{\mathrm{m}} v s$. polymer composition curve of the TrFE-VDF copolymer system shows a minimum point at the intermediate ranges of polymer composition.

According to Natta and coworkers, ${ }^{49}$ isomorphism occurs when the dimensions of the isomorphous molecules are slightly different. The van der Waal's radius of fluorine $(1.35 \AA)$ is slightly different from that of hydrogen $(1.25 \AA)$, and that the $\mathrm{C}-\mathrm{H}$ and $\mathrm{C}-\mathrm{F}$ bond distances are not very different (1.10 and $1.35 \AA$, respectively). ${ }^{50}$ Thus, the difference in the molecular dimension between TrFE and VDF units is thought to be very little.

In the TrFE-VDF copolymer system, the $T_{\mathrm{m}} v s$. polymer composition curve takes minimum point at $90 \mathrm{~mol} \% \mathrm{VDF}$ content. This point corresponds to the point of change in crystal form ( $\alpha$ - to $\beta$-form).

\section{Transitions of VDF-Rich Copolymers}

Figure 6 shows the temperature dependence of dynamic tensile modulus, $E^{\prime}$, and loss tangent, $\tan \delta$, for VDF-rich copolymers (sample A-9 and A-10) and PVDF (sample A-12). The $\alpha$-transition peak in PVDF becomes clear and sharp with increasing TrFE content in the copolymer, and its peak position shifts to a lower temperature. On the contrary, the peak intensity decreases with increasing TrFE content. The $\beta$-transition peak in PVDF also becomes sharp with increasing TrFE content, and the peak position shifts to a higher temperature. The intensities of the $\beta$ - and $\gamma$-transition peaks largely decrease with increasing TrFE content. The dynamic tensile modulus $E^{\prime}$ of VDF-rich copolymers is higher than that of PVDF.

Since the introduction of a second component usually disturbs the crystal lattice, the VDF-rich 


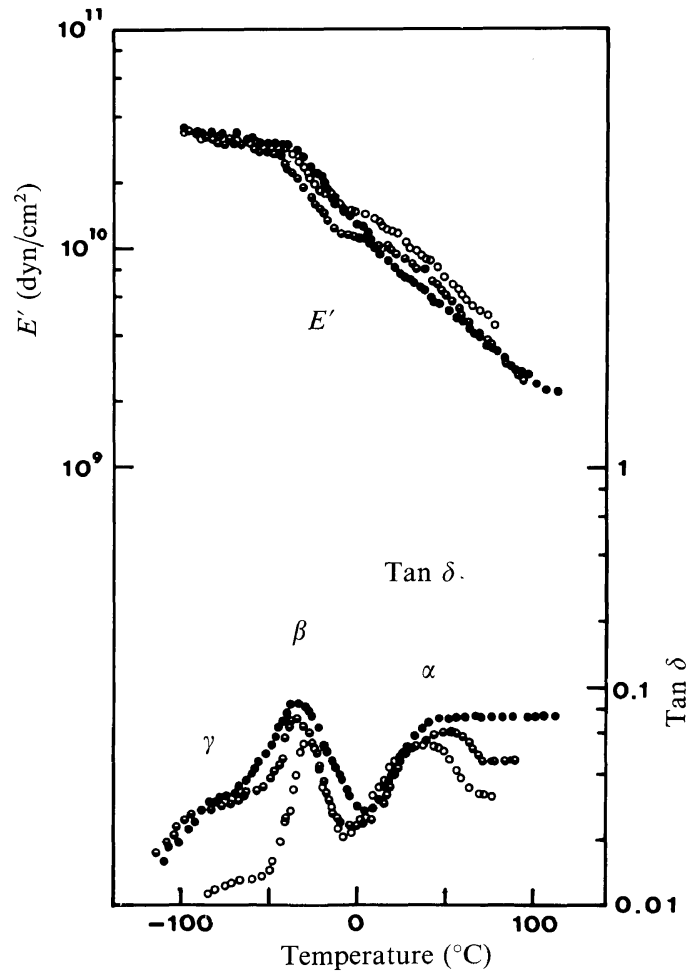

Figure 6. Temperature dependence of dynamic tensile modulus $\left(E^{\prime}\right)$ and loss tangent $(\tan \delta)$ for the VDF-rich copolymers (sample A-9 and A-10) and PVDF (sample A12) measured at $35 \mathrm{~Hz}: \mathrm{O}, \mathrm{A}-8$; $\odot$, A-9; $\odot$ A-10.

copolymer contains many crystalline defects. According to the literature, ${ }^{13}$ the $\alpha$-transition in PVDF is related to the molecular motions of both crystalline defects and lamellar surfaces. Since the degree of the crystallinity does not decrease much with increasing TrFE content, the effect of crystalline defects on the $\alpha$-transition seems little. The increase in $E^{\prime}$ with increasing VDF content seems to be related to the conformational change in the crystal form, from the $\alpha$ - to $\beta$-form.

Figure 7 shows the temperature dependence of dielectric constant $\varepsilon^{\prime}$ and dielectric loss $\varepsilon^{\prime \prime}$ of VDFrich copolymers and PVDF at $30 \mathrm{~Hz}$. These measurements were carried out at frequencies ranging from $30 \mathrm{~Hz}$ to $300 \mathrm{kHz}$. Data from other frequencies were omitted from the figures for clearness. As is seen from the figure, three transition peaks were clearly observed in PVDF, corresponding to mechanical data. The $\alpha$-transition peak is sensible to the dielectric measurement

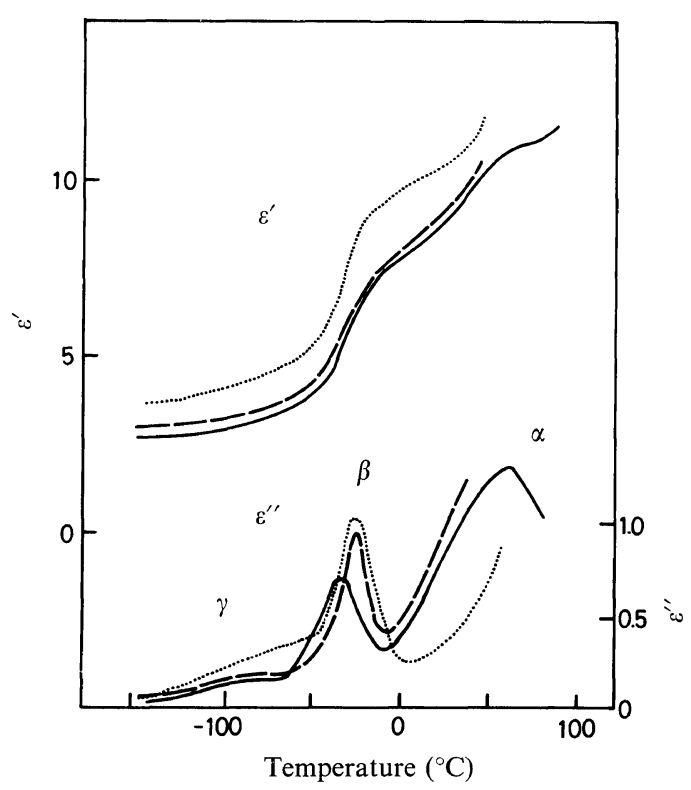

Figure 7. Temperature dependence of dielectric constant $\left(\varepsilon^{\prime}\right)$ and dielectric loss $\left(\varepsilon^{\prime \prime}\right)$ for the VDF-rich copolymers (sample A-9 and A-10) and PVDF (sample A12) measured at $30 \mathrm{~Hz}:-$, PVDF; - -, $90 \mathrm{VDF} ; \cdots, 85$ VDF.

compared to the mechanical measurement. The $\alpha$ transition peak of sample A-10 (90 mol $\%$ VDF) and sample A-9 ( $85 \mathrm{~mol} \%$ VDF $)$ were not observed, since a rapid increase in $\varepsilon^{\prime \prime}$ due to the ionic conductance predominated in the high temperature region.

The dielectric constant of PVDF increases with increasing TrFE content, throughout the entire temperature range. As mentioned above, the polymer chain in sample A-9 takes on the trans or trans-like conformation in crystal. Therefore, it is considered that the polymer chain in the amorphous region also takes on a trans or trans-like conformation in large areas. The effective dipole moment of the trans conformation is preferable to that of the $T G T G^{\prime}$ conformation.

Figure 8 shows the $1 / T v s . f_{\max }$ curves of these copolymers in the $\beta$-transition region. The shapes of the curves resemble each other, and the WLF type $^{51,52}$ The curve of PVDF shifts to the upper temperature side with increasing TrFE content.

\section{Transitions of the TrFE-VDF Copolymers}

Figures 9, 10, and 11 show the temperature dependence of $E^{\prime}$ and $\tan \delta$ for the TrFE-VDF 


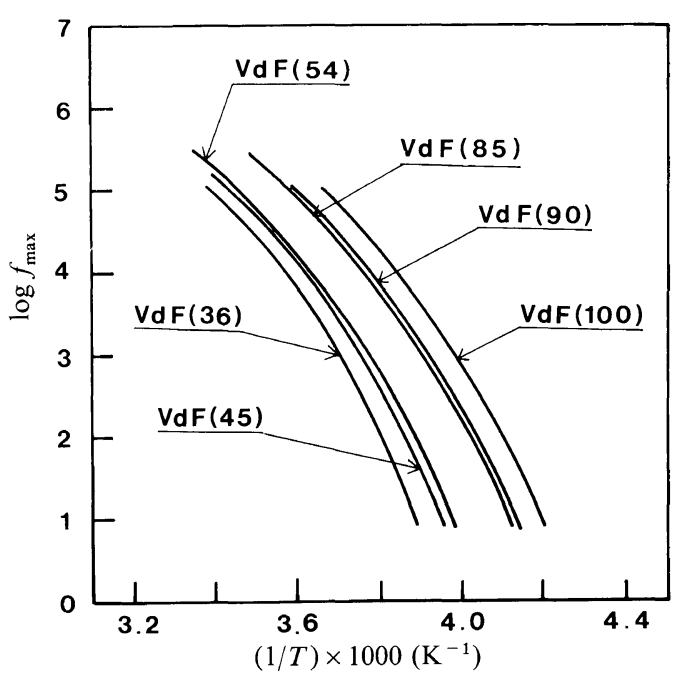

Figure 8. Dispersion map of TrFE-VDF copolymers and PVDF, illustrated by the logarithm frequency $v s$. reciprocal absolute temperature at loss maximum in the $\beta$-transition region.

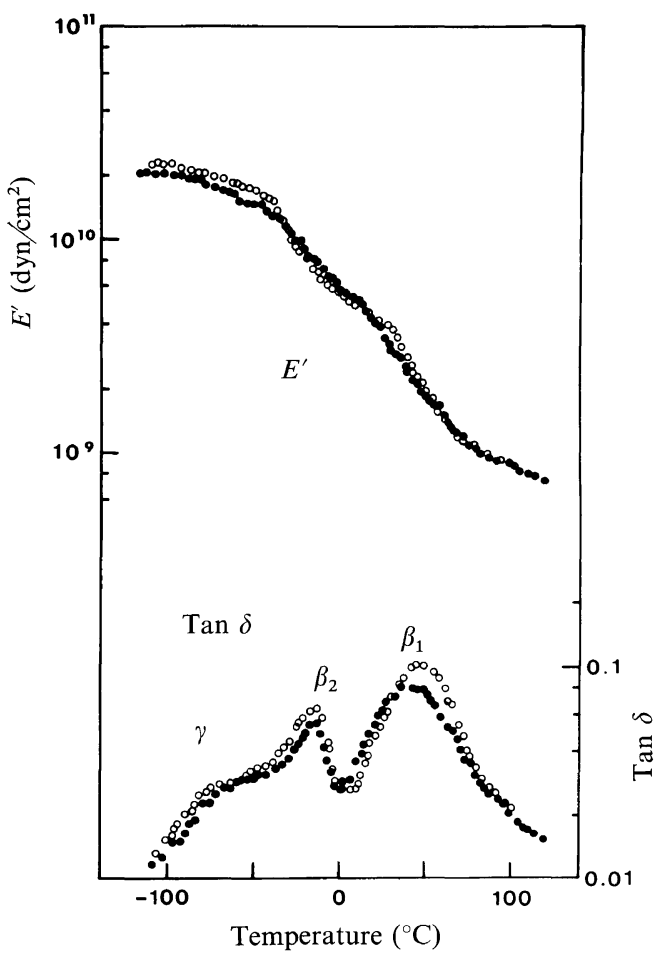

Figure 9. Temperature dependence of dynamic tensile modulus $\left(E^{\prime}\right)$ and loss tangent $(\tan \delta)$ for the TrFE-VDF copolymers (sample A-3 and A-4) measured at $35 \mathrm{~Hz}$ : $\bigcirc$, A-3; O, A-4.

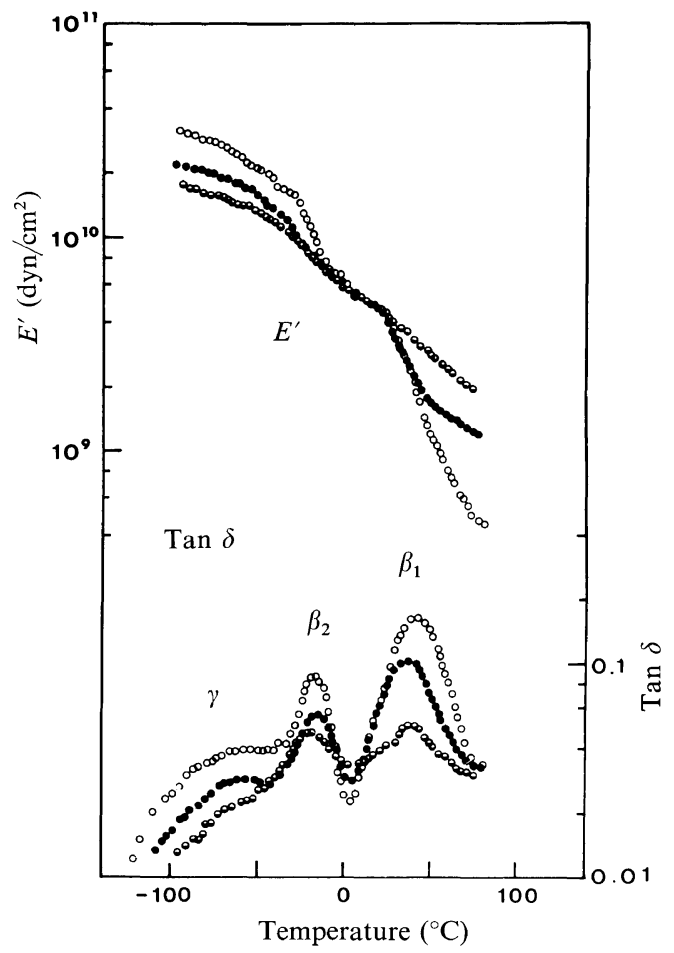

Figure 10. Temperature dependence of dynamic tensile modulus $\left(E^{\prime}\right)$ and loss tangent $(\tan \delta)$ for three samples of the 56:44 TrFE-VDF copolymer (sample A-5) at different crystallinity measured at $35 \mathrm{~Hz}: \bigcirc, \mathrm{A}-5-1 ; \bigcirc, \mathrm{A}-$ 5-2; $\ominus$, A-5-3.

copolymers (sample A-3, A-4, A-5, A-6, and A-7) in the temperature region from -120 to $100^{\circ} \mathrm{C}$ and at $35 \mathrm{~Hz}$. As seen from the figures, the mechanical data of these copolymers resemble each other, except for the upper temperature side peak observed in sample A-7. This peak seems to be due to the $T_{\mathrm{m}}{ }^{\prime}$ transition. In this section, we will describe mainly the mechanical relaxation of sample A-5 (44 mol\% VDF).

The temperature dependences of $E^{\prime}$ and $\tan \delta$ for three samples of the $56: 44 \mathrm{TrFE}-\mathrm{VDF}$ copolymer at different crystallinities are shown in Figure 10. In the temperature region from -120 to $100^{\circ} \mathrm{C}$, three transition regions were observed with peaks at $40^{\circ} \mathrm{C}$ (designated as $\beta_{1}$ ), $-20^{\circ} \mathrm{C}$ (designated as $\beta_{2}$ ), and $-70^{\circ} \mathrm{C}$ (designated as $\gamma$ ), respectively, at $35 \mathrm{~Hz}$. These three transitions show crystallinity dependence and the magnitude of each peak decreases with increasing crystallinity. This result indicates that these three transitions are related to 


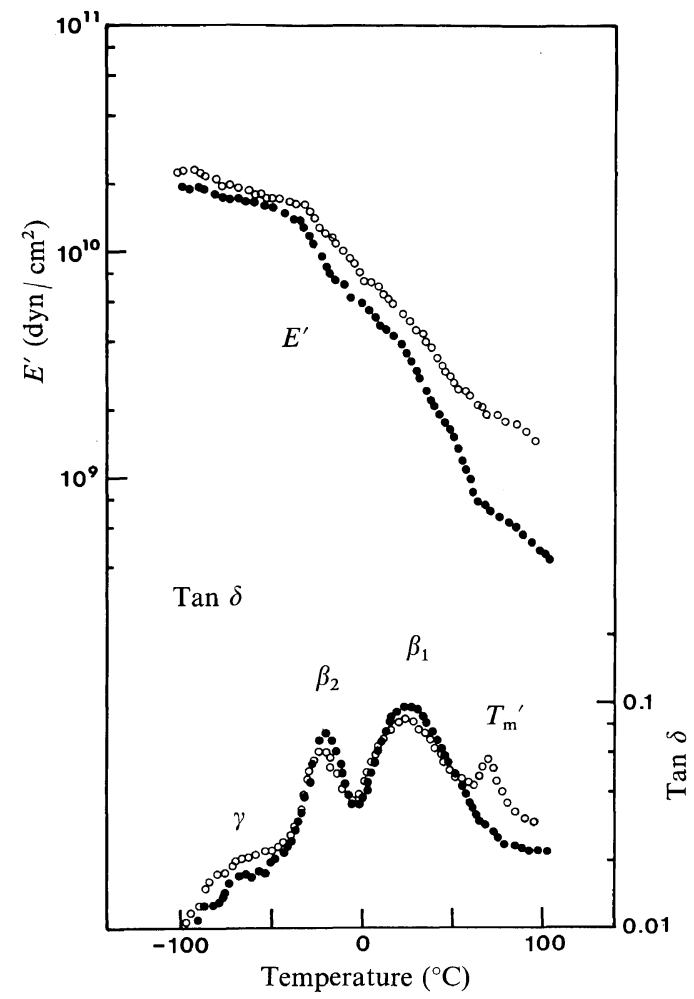

Figure 11. Temperature dependence of dynamic tensile modulus $\left(E^{\prime}\right)$ and loss tangent $(\tan \delta)$ for the TrFE-VDF copolymers (sample A-6 and A-7) measured at $35 \mathrm{~Hz}$ :

A-6; O, A-7.

molecular motion in the amorphous region. The maximum temperatures of the $\beta_{1}$ - and $\beta_{2}$-transition peaks are independent of the degree of crystallinity.

Figure 12 shows the thermal expansion data of the 56:44 TrFE-VDF copolymer (sample A-5). Two break points observed at $40^{\circ} \mathrm{C}$ and at $-29^{\circ} \mathrm{C}$ indicate the presence of two glass-to-rubber transitions, designated as $T_{\mathrm{g} 1}$ (upper break) and $T_{\mathrm{g} 2}$ (lower break), respectively. Figure 10 shows that the $\beta_{1}$ - and $\beta_{2}$-transitions are related to $T_{\mathrm{g} 1}$ and $T_{\mathrm{g} 2}$, respectively.

Figure 13 shows the change in both the $\beta_{1}$ - and $\beta_{2}$ transition temperatures with polymer composition. As seen from the figure, the $\beta$-transition observed in PVDF changes to the $\beta_{2}$-transition in the TrFEVDF copolymer and the $\beta$-transition observed in PTrFE changes to the $\beta_{1}$-transition in the TrFEVDF copolymer. Therefore, it is reasonable to consider that $T_{\mathrm{g} 1}$ is closely related to the glass transition in PTrFE, and $T_{\mathrm{g} 2}$ to that of PVDF.

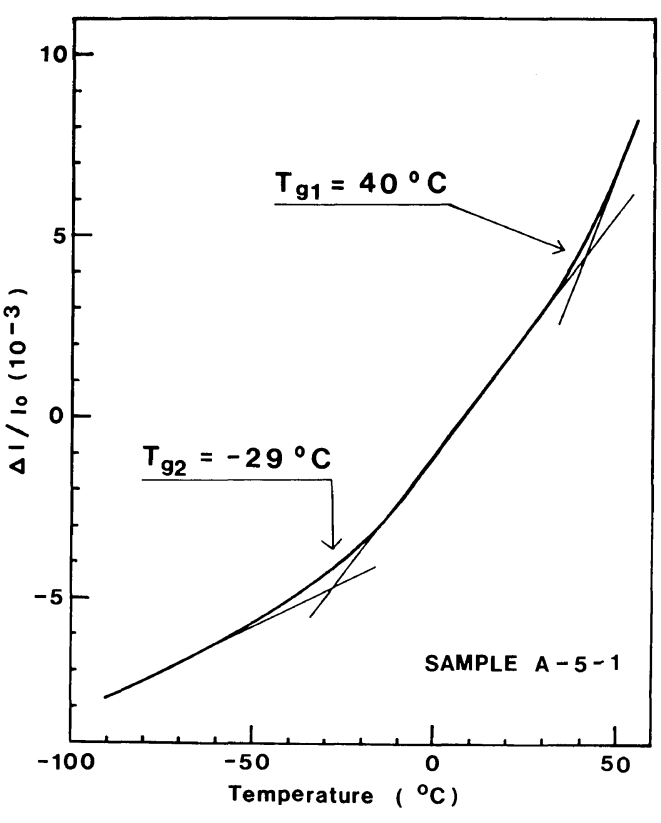

Figure 12. Linear thermal expansion of the $56: 44$ TrFE-VDF copolymer (sample A-5).

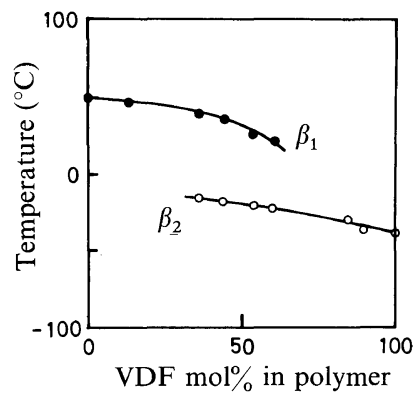

Figure 13. Change in peak temperatures of both the $\beta_{1}$ and $\beta_{2}$-transitions with polymer composition.

The monomer reactivity ratios $\left(r_{1}\right.$ and $\left.r_{2}\right)$ and the high-resolution ${ }^{19} \mathrm{~F}$ NMR studies indicated that the TrFE-VDF copolymers are random copolymers, as mentioned above. Here, we should like to consider the microstructure of the TrFE-VDF copolymer in the following: in segments of the same limited degree of length, there are two parts, one rich in TrFE-units and the other rich in VDF-units, since both monomer units are not arranged in a polymer chain in an alternating or block-like manner. Furthermore, it must be noted here that the difference in molecular 
dimension between TrFE and VDF units is thought to be very little, as mentioned above. Therefore, it is speculated that the small amount of VDF-units in a TrFE-rich sequence or the small amount of TrFEunits in a VDF-rich sequence may not affect the molecular motions very much. Thus, we consider that $T_{\mathrm{g} 1}$ is related to the amorphous region rich in TrFE-units and $T_{\mathrm{g} 2}$, to the amorphous region rich in VDF-units. Such double $T_{\mathrm{g}}$ were observed in many semicrystalline polymers. ${ }^{53,54,55}$

These $\beta_{1}$ - and $\beta_{2}$-transitions of the TrFE-VDF copolymers were also observed in broad-line NMR measurements. ${ }^{56}$ Judging from the variation of the fluorine resonance line width with temperature, the solid to liquid transition seems to occur at the $\beta_{1}$ transition.

Figures 14 and 15 show the frequency dependence of $\varepsilon^{\prime}$ and $\varepsilon^{\prime \prime}$ of the 46:54 TrFE-VDF copolymer in the frequency region from $30 \mathrm{~Hz}$ to $300 \mathrm{kHz}$ and at temperatures indicated in the figures. Two distinct peaks, $\beta_{2}$ and $\gamma$, corresponding to the mechanical relaxation study, are also observed, as seen in Figure 11. The $\beta_{1}$-transition peak was not observed, since a rapid increasing of $\varepsilon^{\prime \prime}$ due to ionic conductance predominated at high temperatures.

Figure 16 shows the dispersion map of the $46: 54$

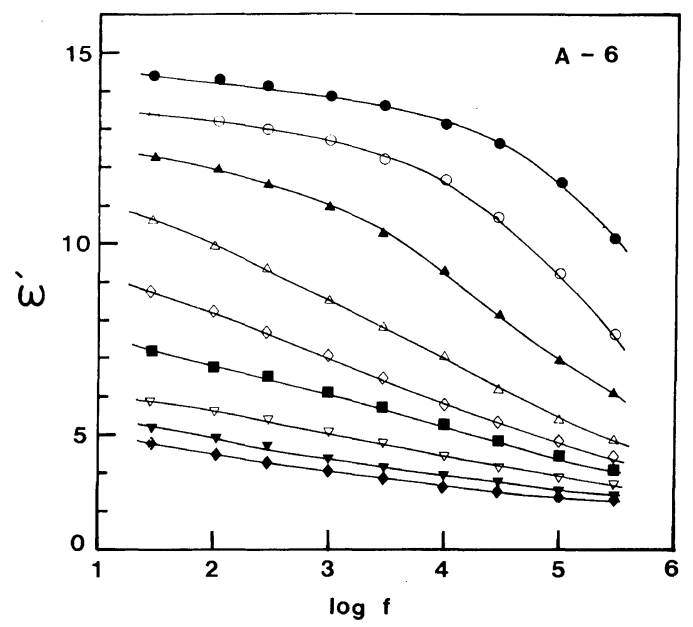

Figure 14. Frequency dependence of dielectric constant $\left(\varepsilon^{\prime}\right)$ of the $46: 54 \mathrm{TrFE}-\mathrm{VDF}$ copolymer (sample A-6) in the frequency region of $30 \mathrm{~Hz}$ to $300 \mathrm{kHz}:-22.0^{\circ} \mathrm{C} ; \mathrm{O}$, $11.0^{\circ} \mathrm{C} ; \boldsymbol{\Delta},-2.0^{\circ} \mathrm{C}: \triangle,-12.5^{\circ} \mathrm{C} ; \diamond,-20.0^{\circ} \mathrm{C}$; $-27.5^{\circ} \mathrm{C} ; \triangle,-40.5^{\circ} \mathrm{C} ; \boldsymbol{\Delta},-53.0^{\circ} \mathrm{C} ; \diamond,-63.0^{\circ} \mathrm{C}$.

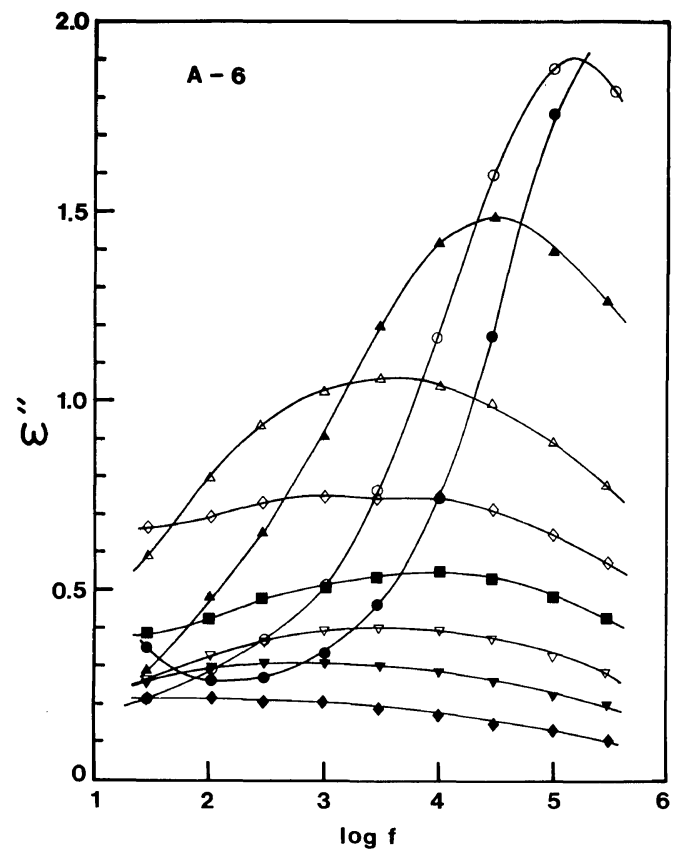

Figure 15. Frequency dependence of dielectric loss $\left(\varepsilon^{\prime \prime}\right)$ of the 46:54 TrFE-VDF copolymer (sample A-6) in the frequency region of $30 \mathrm{~Hz}$ to $300 \mathrm{kHz}:-22.0^{\circ} \mathrm{C} ; \mathrm{O}$, $11.0^{\circ} \mathrm{C} ; \boldsymbol{\Delta},-2.0^{\circ} \mathrm{C} ; \triangle,-12.5^{\circ} \mathrm{C} ; \diamond,-20.0^{\circ} \mathrm{C} ;$ $-27.5^{\circ} \mathrm{C} ; \triangle,-40.5^{\circ} \mathrm{C} ; \boldsymbol{\Delta},-53.0^{\circ} \mathrm{C} ; \bullet,-63.0^{\circ} \mathrm{C}$

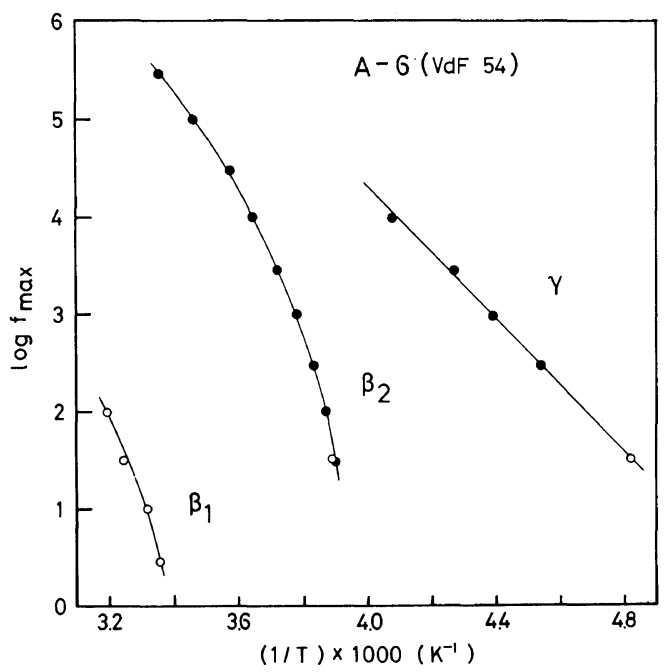

Figure 16. Dispersion map of the $46: 54$ TrFE-VDF copolymer (sample A-6), illustrated by the logarithm frequency vs. reciprocal absolute temperature at loss maximum in both dielectric (O) and mechanical (O) measurements. 
TrFE-VDF copolymer, which illustrates the logarithm of frequency $v s$. the reciprocal absolute temperature at loss maximum in both dielectric and mechanical measurements. The curve of $\log f_{\max } v s$. $1 / T$ of the $\beta_{2}$-transition is of the WLF type. ${ }^{51,52}$ However, it is difficult to decide whether the $\beta_{1}$ transition satisfies the WLF equation or not, since the employed data are very few. The activation energy $\Delta H$ was obtained from a plot of $\log f_{\max } v s$. $1 / T$, using the following equation,

$$
\Delta H=-2.303 R \mathrm{~d}\left(\log f_{\max }\right) / \mathrm{d}(1 / T)
$$

where $R$ is the gas constant and $T$ the absolute temperature. Temperature dependence of $\Delta H$ for the $\beta_{1^{-}}, \beta_{2^{-}}$, and $\gamma$-transitions are shown in Figure 17.

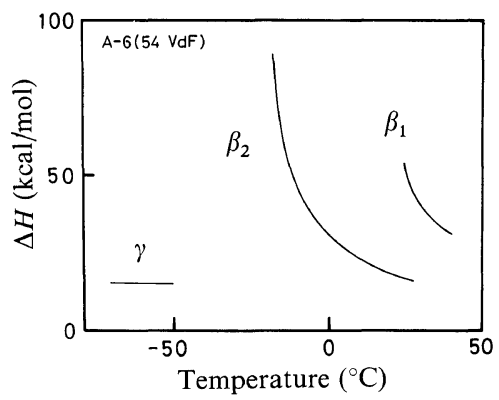

Figure 17. Temperature dependence of the activation energy $\Delta H$ for the $\beta_{1}, \beta_{2}$, and $\gamma$ relaxations of the $46: 54$ TrFE-VDF copolymer (sample A-6).

For example, the $\Delta H$ of $\beta_{1}$-transition is about $38 \mathrm{kcal}$ $\mathrm{mol}^{-1}$ at $30^{\circ} \mathrm{C}$, and that of the $\beta_{2}$-transition is about $37 \mathrm{kcal} \mathrm{mol}^{-1}$ at $-5^{\circ} \mathrm{C}$. These values are quite similar to the activation energies of both PTrFE and PVDF in the glass-to-rubber transition regions: the $\Delta H$ of $\mathrm{PTrFE}$ in glass-to-rubber transition region is about $40 \mathrm{kcal} \mathrm{mol}^{-1}$ at $40^{\circ} \mathrm{C},{ }^{3}$ and that of PVDF is about $33 \mathrm{kcal} \mathrm{mol}^{-1}$ at $25^{\circ} \mathrm{C}$.

The plots of the logarithm of frequency vs. reciprocal absolute temperature of the TrFE-VDF copolymers (samples A-4, A-5, and A-6) in the $\beta_{2}$ transition region are also shown in Figure 8. The slopes of these curves are similar to that of PVDF. These results also show that the $\beta_{2}$-transition is closely related to the glass-to-rubber transition of PVDF.

According to WLF theory, ${ }^{51} \Delta H$ is related to the freezing temperature, $T_{\mathrm{c}}$, of molecular motion by,

$$
\Delta H=2.303 R c_{1} c_{2} T^{2} /\left(c_{2}+T-T_{\mathrm{c}}\right)
$$

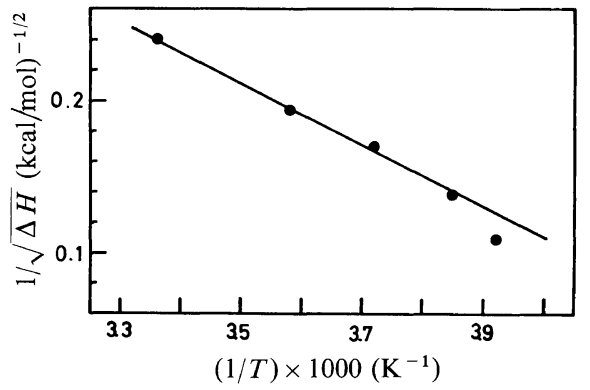

Figure 18. Plot of $1 / \sqrt{\Delta H}$ vs. $1 / T$ for the $\beta_{2}$-transition the $46: 54$ TrFE-VDF copolymer (sample A-6).

where $R$ is the gas constant, and $c_{1}$ and $c_{2}$ are constants Figure 18 shows a plot of $1 / \sqrt{\Delta H} v s .1 / T$ for the $\beta_{2}$-transition of the 56:44 TrFE-VDF copolymer. The data shows a linear relationship in the temperature range from -12 to $25^{\circ} \mathrm{C}$ (satisfying the WLF theory).

From these results and discussion, we consider that the $\beta_{1}$-transition is related to the microBrownian motion of the main chain in the amorphous region rich in TrFE units; the $\beta_{2}$ transition is assigned to the micro-Brownian motion of the main chain in the amorphous region rich in VDF units.

The $\gamma$-transition of the 46:54 TrFE-VDF copolymer is observed in both mechanical and dielectric measurements, as seen in Figures 10 and 15. The $\gamma$-transition is also affected by the crystallinity of samples like the $\beta_{1^{-}}$and $\beta_{2}-$ transitions, and the magnitude of its peak decreases with increasing crystallinity. The $\gamma$-transition is observed below the lower glass-to-rubber transition temperature, $T_{\mathrm{g} 2}$, of $-29^{\circ} \mathrm{C}$. Therefore, the $\gamma$ transition is a local molecular motion in the amorphous region. A plot of the logarithm of the frequency $v s$. the reciprocal absolute temperature of the loss maximum for $\gamma$-transition region in the 46:54 TrFE-VDF copolymer is also shown in Figure 16. The curve is linear in the temperature region from -50 to $-65^{\circ} \mathrm{C}$. The activation energy is found to be about $15 \mathrm{kcal} \mathrm{mol}^{-1}$. This transition is thought to be similar to the local molecular motion in PVDF, since the $\gamma$-transition in PVDF is also related to the amorphous region and the $\Delta H$ is very small $\left(\Delta H=14 \mathrm{kcal} \mathrm{mol}^{-1}\right)^{57}$ as in the case of the TrFE-VDF copolymers. On the other hand, local 
molecular motion of PTrFE is related to both the crystal and the amorphous region, and the $\Delta H$ is very large $\left(28 \mathrm{kcal} \mathrm{mol}^{-1}\right) .^{3}$

\section{Transition Map}

Figure 19 shows the changes in the transition temperatures with the polymer composition. The primary and secondary melting temperatures $\left(T_{\mathrm{m}}\right.$ and $T_{\mathrm{m}}{ }^{\prime}$ ) were determined by the DSC measurement, and the other transition temperatures were determined by mechanical relaxation measurements at $35 \mathrm{~Hz}$.

\section{Analysis of Dielectric Properties}

Figure 20 shows the change in the dielectric constant $\varepsilon^{\prime}$ with polymer composition at $1 \mathrm{kHz}$ and at $22^{\circ} \mathrm{C}$. Figure 21 shows a temperature dependence of $\varepsilon^{\prime}$ of PTrFE (sample A-1), the 46:54 TrFE-VDF copolymer (sample A-6), and PVDF (sample A-12). It is also seen that $\varepsilon^{\prime}$ of the copolymer always has a high value compared with that of both homopolymers throughout the temperature region investigated here. The TrFE-VDF copolymers are characterized by a high value of $\varepsilon^{\prime}$.

The high value of dielectric constant of a semicrystalline polymer depends on (1) the

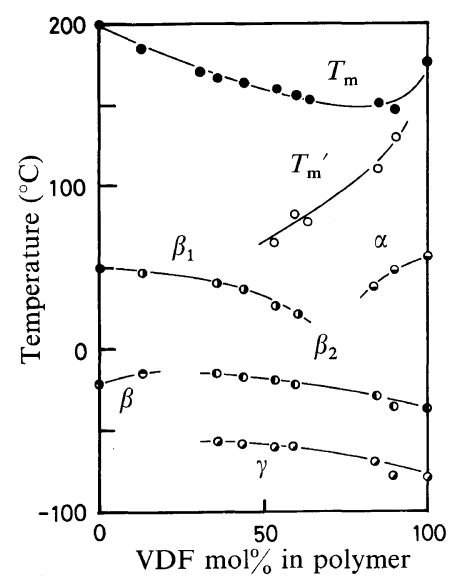

Figure 19. Change in transition temperatures with polymer composition. The primary and secondary melting temperatures $\left(T_{\mathrm{m}}\right.$ and $\left.T_{\mathrm{m}}{ }^{\prime}\right)$ are determined by DSC measurement. Other transition temperatures are determined by mechanical relaxation measurement at $35 \mathrm{~Hz}$.

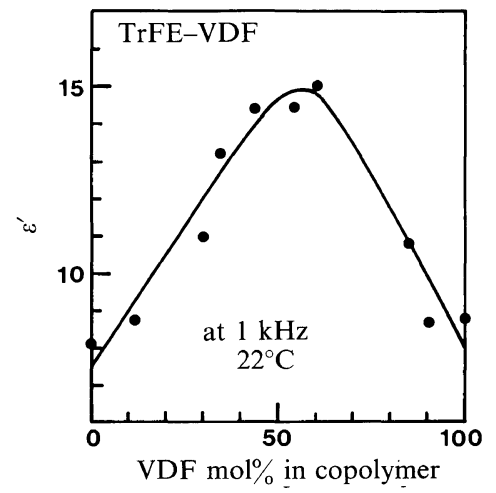

Figure 20. Change in dielectric constant $\left(\varepsilon^{\prime}\right)$ with polymer composition at $1 \mathrm{kHz}$ and at $22^{\circ} \mathrm{C}$.

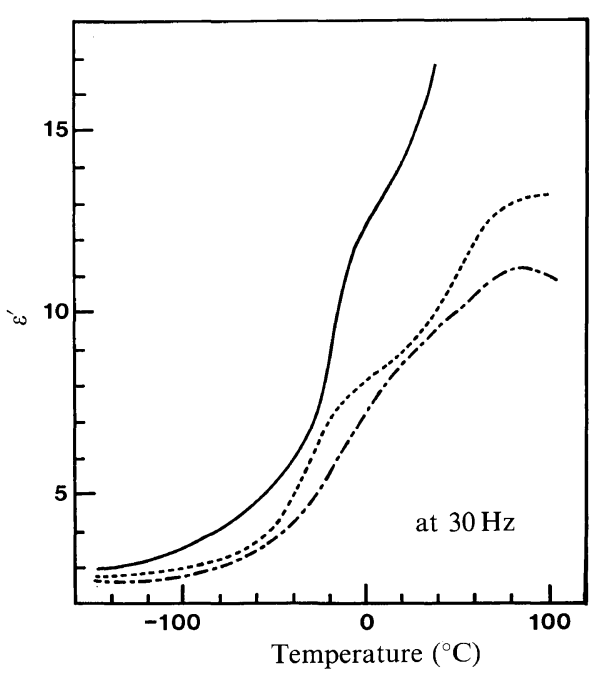

Figure 21. Change in dielectric constant $\left(\varepsilon^{\prime}\right)$ of PTrFE, the 46:54 TrFE-VDF copolymer (sample A-6), and PVDF with temperature at $30 \mathrm{~Hz}:-\cdot-\cdot$, PTrFE; VDF (54); ----, PVDF.

magnitude of the dipole moment of repeating units, (2) the position and direction of the dipole with respect to the chain backbone, (3) the freedom of the dipole rotation in the electric field, and (4) the crystal form of the polymer, i.e., the possibility of a spontaneous polarization in the crystal. These terms are discussed in the following. 
The Magnitude of the Dipole Moment. The effective dipole moment for a repeating unit of PTrFE is 1.63 Debye for the trans and gauche $(+)$ conformations, and 3.25 Debye for the gauche (-) conformation, respectively, and that of PVDF is 1.96 Debye. ${ }^{3}$ These values seem very large compared with other monomeric units.

The Position and Direction of the Dipole. In polar polymers the existence of head-to-head structures of repeating units will considerably affect the dielectric properties. PVDF has about $8 \%$ head-to-head structures in the polymer chain, ${ }^{58}$ and this material shows a high dielectric constant $\left(\varepsilon^{\prime}=8.5\right.$ at $1 \mathrm{kHz}$ and at $22^{\circ} \mathrm{C}$ ). On the other hand, $\varepsilon^{\prime}$ of ethylene (E)tetrafluoroethylene (TFE) copolymer having 100\% head-to-head structures is very small $\left(\varepsilon^{\prime}=2.6\right.$ at 1 $\mathrm{kHz}$ and at $\left.22^{\circ} \mathrm{C}\right)^{59,60}$. In the case of the E-TFE copolymer system, the effective dipole moments canceled each other out in the chain.

A high resolution fluorine-19 NMR study indicated that the microstructure of the TrFE-VDF copolymer chain is characterized by the $-\mathrm{CF}_{2}-\mathrm{CH}_{2}-$ $\mathrm{CF}_{2}-\mathrm{CFH}-\mathrm{CF}_{2}-^{2}$. This microstructure arises from the head-to-tail structure of TrFE-VDF (and/or VDF-TrFE) sequence. Here, the $\mathrm{CF}_{2}$-position of both the TrFE $\left(\mathrm{CF}_{2}=\mathrm{CFH}\right)$ and $\operatorname{VDF}\left(\mathrm{CF}_{2}=\mathrm{CH}_{2}\right)$ is the head-position, and the other position $(\mathrm{CFH}$ or $\left.\mathrm{CH}_{2}\right)$ is the tail-position. Figure 22 shows the normalized fraction of the head-to-tail structure in the TrFE-TrFE, TrFE-VDF (VDF-TrFE) and VDF-VDF sequences as a function of the polymer composition, obtained from NMR data. The broken lines represent the monomer diad sequence distribution curves containing head-to-tail, head-tohead, tail-to-tail, and tail-to-head sequences. These data were obtained from high resolution ${ }^{19} \mathrm{~F}$ NMR measurements. (The details for the NMR study of copolymers are described elsewhere. ${ }^{2}$ ) The amount of head-to-head structures of the TrFE-VDF (and/or VDF-TrFE) sequences in the copolymer chain is rather abundant. The content of this microstructure shows a maximum at $55 \mathrm{~mol} \% \mathrm{VDF}$ content. This polymer composition corresponds to that of the maximum point of dielectric constant.

Freedom of the Dipole Rotation. The dielectric properties should be, actuality more sensible to the dipole motion in the amorphous region than the crystalline region in the electric field. The large scale molecular motion in the amorphous region also is

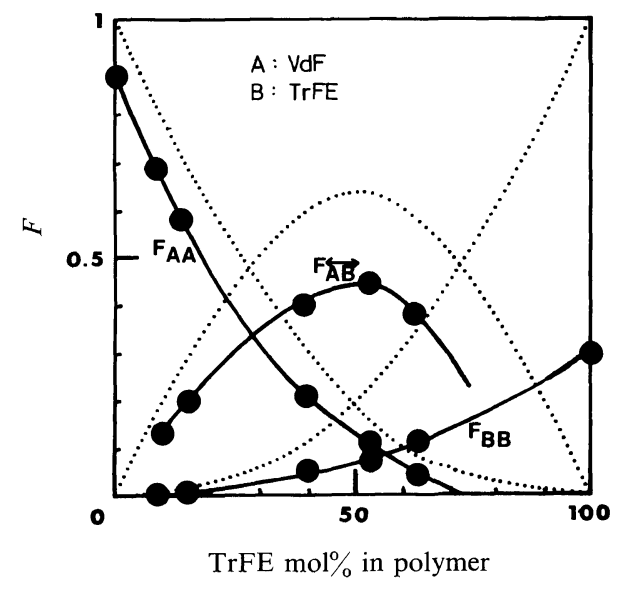

Figure 22. Normalized fractions of monomer diads, in the head-to-tail structure of TrFE-TrFE, TrFE-VDF, and VDF-VDF sequences, as functions of polymer composition for TrFE-VDF copolymer system, (-). And normalized monomer diad fractions containing head-to-tail, head-to-head, tail-to-tail, and tail-to-head structures, (-----). Symbols A and A represent VDF and TrFE, respectively. These data are taken from ref 2 .

necessary to observe a high $\varepsilon^{\prime}$ value. The value of $\varepsilon^{\prime}$ changes considerably between the below and above glass transition temperatures. In the $56: 44 \mathrm{TrFE}-$ VDF copolymer, the lower glass-to-rubber transition is observed below room temperature, $\left(T_{\mathrm{g} 2}=-29^{\circ} \mathrm{C}\right)$.

The dielectric rotation is correlated with the magnitude of the dielectric relaxation. The magnitude of the dielectric relaxation, $\Delta \varepsilon$, is given by,

$$
\Delta \varepsilon=\varepsilon_{0}-\varepsilon_{\infty}
$$

where $\varepsilon_{0}$ is the static dielectric constant and $\varepsilon_{\infty}$ is the dielectric constant at a very high frequency at which no orientation of any dipoles takes place. The value of $\Delta \varepsilon$ can be obtained from the Cole-Cole plot, ${ }^{61}$ or be obtained from the area under a plot of $\varepsilon^{\prime \prime} v s . \ln f$, by the following equation, ${ }^{62}$

$$
\varepsilon_{0}-\varepsilon_{\infty}=\frac{2}{\pi} \int_{-\infty}^{\infty} \varepsilon^{\prime \prime} \mathrm{d}(\ln f)
$$

According to the Fröhlich-Kirkwood theory, ${ }^{63}$ the dielectric permittivity is expressed as,

$$
\Delta \varepsilon=\varepsilon_{0}-\varepsilon_{\infty}=\frac{3 \varepsilon_{0}}{2 \varepsilon_{0}+\varepsilon_{\infty}} \frac{4 \pi N}{3 k T}\left(\frac{\varepsilon_{\infty}+2}{3}\right)^{2} g_{\mathrm{r}} \mu_{0}^{2}
$$


Table II. Kirkwood reduction factor $g_{\mathrm{r}}$ for the $44: 56$ TrFE-VDF copolymer in temperature region of the $\beta_{2}$-transition

\begin{tabular}{clcccc}
\hline Temperature & & & & & \\
\cline { 1 - 3 }${ }^{\circ} \mathrm{C}$ & $\varepsilon_{\infty}$ & $\varepsilon_{0}$ & $\Delta \varepsilon$ & $\bar{\mu}^{2}$ & $g_{\mathbf{r}}$ \\
\hline-62 & 3.0 & 5.45 & 2.45 & 1.79 & 0.47 \\
-53 & 3.0 & 5.80 & 2.80 & 2.12 & 0.55 \\
-40.5 & 3.10 & 6.50 & 3.35 & 2.48 & 0.65 \\
-28 & 3.15 & 7.70 & 4.55 & 3.45 & 0.90 \\
-13 & 3.5 & 10.80 & 7.30 & 4.65 & 1.21 \\
\hline
\end{tabular}

where $N$ is the concentration of the repeating unit, $\mu_{0}$ the dipole moment, $g_{\mathrm{r}}$ the Kirkwood reduction factor expressed as an average of the special orientation, $k$, the Boltzmann constant, and $T$ the absolute temperature. The values of $\varepsilon_{0}$ and $\varepsilon_{\infty}$ were estimated by the Cole-Cole plot. The $g_{\mathrm{r}}$ value of the TrFEVDF copolymer is calculated by assuming that $\Delta \varepsilon$ arises mainly from the dipole orientation in VDFrich amorphous phase at the $\beta_{2}$-transition region. $N$ is given by,

$$
N=N_{\mathrm{A}} f_{\mathrm{A}} X_{\mathrm{A}} / M_{\mathrm{o}} V_{\mathrm{s}}
$$

where $N_{\mathrm{A}}$ is Avogadro's number, $M_{\mathrm{o}}$ the molecular weight of the repeating unit, $V_{\mathrm{s}}$ the specific volume, $f_{\mathrm{A}}$ the weight fraction of amorphous region, and $X_{\mathrm{A}}$ the molar fraction of VDF in the copolymer. The values of $V_{\mathrm{s}}$ and $f_{\mathrm{A}}$ are taken from Table $\mathrm{I}$. The calculated values of $g_{\mathrm{r}}$ and $g_{\mathrm{r}} \times \mu_{0}{ }^{2}\left(=\mu^{2}\right)$ are tabled in Table II, together with the values of $\varepsilon_{0}, \varepsilon_{\infty}$, and $\Delta \varepsilon$. From these results, it is speculated that the free rotation of dipole moment of the VDF-unit may occur in the $\beta$-transition region.

Crystal Form. As mentioned above, the crystal form of the TrFE-VDF copolymers (12.5 to 85 $\mathrm{mol} \% \mathrm{VDF}$ ) is quite similar to that of the $\beta$-form crystal of PVDF, and the main chain takes on a trans conformation in crystal. According to Nakamura and $\mathrm{Wada}^{30}{ }^{30}$ the $\beta$-form PVDF crystal has a spontaneous polarization and this material is classified as a ferroelectric polymer. It is considered that the TrFE-VDF copolymer also has a ferroelectric nature similar to the $\beta$-form PVDF crystal. (We are now carrying out studies on the electric behavior of the TrFE-VDF copolymers at our laboratory.)

The trans conformation of the TrFE-VDF copolymer seems to hold locally in the amorphous region. These crystal morphology and chain conformation seem to contribute much to the dielectric properties.

Acknowledgements. The authors wish to thank Professor Akio Nakajima of Kyoto University for his valuable comments and suggestions, and to Dr. Yoshihiko Kubouchi and Dr. Yutaka Kometani of Daikin Kogyo Co., Ltd., for their stimulating discussions and encouragement.

\section{REFERENCES}

1. T. Yagi, Polym. J., 11, 353 (1979).

2. T. Yagi and M. Tatemoto, Polym. J., 11, 429 (1979).

3. T. Yagi, M. Tatemoto, and J. Sako, Polym. J., 11, 711 (1979).

4. P. D. Schuman, E. C. Stumpant and G. Westmoreland, J. Macromol. Sci., B1(4), 815 (1967).

5. W. K. Lee and C. L. Choy, J. Polym. Sci., Polym. Phys. Ed., 13, 619 (1975).

6. H. Kakutani, J. Polym. Sci., A-2, 8, 1177 (1970).

7. N. K. Kalfoglou and H. L. Williams, J. Appl. Polym. Sci., 17, 3367 (1973).

8. E. J. Parry and D. Tabor, Polymer, 14, 623 (1973).

9. S. P. Kabin, S. G. Malkevich, G. P. Mikhailov, B. I. Sazhin and A. L. V. Chereshkevich, Vysokomol. Soedin., 3, 618 (1961).

10. Y. Ishida, M. Watanabe, and K. Yamafuji, Kolloid Z. Z. Polym., 211, 48 (1964).

11. A. Peterlin and J. Elwell, J. Mater. Sci., 2, 1 (1967).

12. H. Sasabe and S. Saito, Rep. Prog. Polym. Phys. Jpn., 11, 379 (1968).

13. S. Yano, J. Polym. Sci., A-2, 8, 1057 (1970).

14. K. Nakagawa and Y. Ishida, J. Polym. Sci., Polym. Phys. Ed., 11, 1503 (1973).

15. S. Uemura, J. Polym. Sci., Polym. Phys. Ed., 12, 1177 (1973).

16. S. Osaki and Y. Ishida, J. Polym. Sci., Polym. Phys. Ed., 12, 1727 (1974).

17. S. Yano, K. Tadano, K. Aoki, and N. Koizumi, $J$. 
Polym. Sci., Polym. Phys. Ed., 12, 1875 (1974).

18. W. P. Slichter, J. Polym. Sci., 24, 173 (1957).

19. V. J. McBrierty, D. C. Douglass, and T. A. Weber, J. Polym. Sci., Polym. Phys. Ed., 14, 1271 (1976).

20. V. J. McBrierty and D. C. Daglass, Macromolecules, 10, 855 (1977).

21. L. E. Nielsen, "Mechanical Properties of Polymers," Reinhold Publishing Corp., New York, N.Y., 1962.

22. E. L. Galperin and Yu. V. Stroglain, Vysokomolekul. Soedin., 7, 16 (1965); Polym. Sci., USSR, English translation, 7, 15 (1965).

23. R. R. Kolda and J. B. Lando, J. Macromol. Sci.,Phys., B11 (1), 21 (1975).

24. Ye. L. Galperin, Yu. V. Strogalin, and M. P. Mlenik, Vsokomol. Soedin., 7, 933 (1965).

25. J. B. Lando, H. G. Olf, and A. Peter, J. Polym. Sci., $A-1,4,941$ (1966).

26. J. B. Lando and W. W. Doll, J. Macromol. Sci., Phys., 2, 205 (1968).

27. W. W. Doll and J. B. Lando, J. Macromol. Sci., Phys., 2, 309 (1970).

28. R. Hasegawa, Y. Tanabe, M. Kobayashi, and H. Tadokoro, J. Polym. Sci., A-2, 8, 1073 (1970).

29. R. Hasegawa, Y. Takahashi, T. Chatani, and H. Tadokoro, Polym. J., 3, 600 (1972).

30. K. Nakamura and Y. Wada, J. Polym. Sci., A-2, 9, 161 (1971).

31. G. Pfister, M. Abkowitz, and R. G. Crystal, J. Appl. Phys., 44, 2064 (1973).

32. G. Pfister and M. Abkowitz, J. Appl. Phys., 45, 1001 (1974).

33. H. Ohigashi, J. Appl. Phys., 47, 949 (1976).

34. Y. Wada and R. Hayawakawa, Jpn. J. Appy. Phys., 15, 2041 (1976).

35. M. Tamura, S. Hagiwara, S. Matsumoto, and N. Ono, J. Appl. Phys., 48, 513 (1977).

36. H. Lee, R. E. Salomon, and M. M. Labes, Macromolecules, 11, 171 (1978).

37. N. Murayama, J. Polym. Sci., Polym. Phys. Ed., 13, 929 (1975).

38. N. Murayama, T. Oikawa, T. Katto, and K. Nakamura, J. Polym. Sci., Polym. Phys. Ed., 13, 1033 (1975).

39. R. E. Salomon, B. K. Oh, and M. M. Lables, J. Appl.
Phys., 47, 1710 (1976).

40. R. E. Salomon, H. Lee, C. S. Bak, and M. M. Lables, J. Appl. Phys., 47, 4206 (1976).

41. K. Takahashi, H. Lee, R. E. Salomon, and M. M. Lables, J. Appl. Phys., 48, 4694 (1977).

42. P. J. Flory, "Priciple of Polymer Chemistry," Cornell University Press, Ithaca, N.Y., 1953.

43. J. P. Bell, P. E. Slade, and J. H. Dumbleton, J. Polym. Sci., A-2, 6, 1773 (1968).

44. J. P. Bell and J. H. Dumbleton, J. Polym. Sci., A-2, 7, 1033 (1969).

45. S. Enomoto, Y. Kawai, and M. Sugita, J. Polym. Sci., $A-2,6,861$ (1968).

46. M. Kobayashi, K. Tashiro, and H. Tadokoro, Macromolecules, 8, 158 (1975).

47. O. B. Edgar and R. Hill, J. Polym. Sci., 8, 1 (1952).

48. T. C. Tranter, J. Polym. Sci., A-2, 2, 4289 (1964).

49. G. Natta, G. Allefra, W. Bassi, D. Sianesi, G. Caporiccio, and E. Torti, J. Polym. Sci., A, 3, 4263 (1965).

50. L. Pauling, "The Nature of Chemical Bond," Cornell University Press, Ithaca, N.Y., (1961).

51. W. L. Williams, F. F. Landel, and J. D. Ferry, J. Am. Chem. Soc., 77, 3701 (1955).

52. J. D. Ferry, "Viscoelastic Properties of Polymers," Wiley, New York, N.Y., 1961.

53. Y. Wada and Y. Hotta, J. Polym. Sci., C, 23, 583 (1968).

54. R. F. Boyer, J. Macromol. Sci., Phys., B8, 503 (1973).

55. R. F. Boyer, J. Polym. Sci., Polym. Symp., 50, 189 (1975).

56. T. Yagi, unpublished data.

57. P. Hedvig, "Dielectric Spectroscopy of Polymers," Adam Hilger, Budapest, 1977.

58. C. W. Willson, III, J. Polym. Sci., 56, S12 (1962).

59. Du Pont, "Tefzel" Design Handbook, du Pont, 1973.

60. M. Modena, C. Garbuglio, and M. Ragazzini, J. Polym. Sci., B, 10, 153 (1972).

61. K. S. Cole and R. H. Cole, J. Chem. Phys., 9, 314 (1941).

62. T. Nakajima and S. Saito, J. Polym. Sci., 31, 423 (1958).

63. H. Frölich, "Theory of Dielectrics," Oxford University Press, London, 1958. 